\title{
The Influence of Metaphorical Frames on Americans' Adherence to COVID-19 Public Health Guidelines
}

\author{
Elena Singer-Freeman ${ }^{1}$ and Erika Thurman* \\ ${ }^{1}$ Providence High School address, Charlotte, NC, USA \\ \#Advisor
}

\section{$\underline{\text { ABSTRACT }}$}

Metaphors more-effectively influence people's perceptions and behavior than normal language. The type of metaphor used is important in maximizing persuasion. Two common public health metaphors are family and war. War metaphors generally evoke more fear than family metaphors, and family metaphors generally evoke more empathy than war metaphors. The current study investigates whether family metaphors are more effective than war metaphors in promoting adherence to COVID-19 guidelines. Participants were assigned to a condition in which they read a single COVID-19-related paragraph. The paragraph included either family, war, or no metaphorical frame. All groups rated the extent to which reading the paragraph would change an average person's adherence to a variety of public health guidelines. After reading the paragraph, participants reported their perceptions regarding the danger of COVID-19 and their feelings of unity with others to determine whether the metaphor manipulation effectively influenced fear and empathy. There was no observable effect of metaphor type on adherence to public health guidelines. Feelings of unity and fear were not higher, on average, in one group compared to another. Thus, one metaphorical condition or even the presence of a metaphor was not observed to be more effective in changing people's adherence to public health guidelines. Additionally, the metaphors did not evoke their intended emotions, which may explain the lack of change in behavior. Future research investigating the effect of numbing on metaphor effectiveness may help explain these results and indicate whether metaphors should be used for persuasion in future public health crises.

\section{Introduction}

As the United States struggles to keep the COVID-19 pandemic under control, thousands of new cases and hundreds of new deaths are reported per day according to the CDC (Centers for Disease Control and Prevention [CDC], 2021). At the time of writing (5/14/2021), not only has the pandemic led to over 580,000 deaths reported to the CDC in the United States, but it has also negatively impacted the economy (CDC, 2021). Researchers from the National Bureau of Economic Research estimated that, by April 6th, 2020, 20 million people in the U.S. lost their jobs (Coibion et al., 2020).

COVID-19 is the first disease to have dominated the news cycle; in January 2020, the word 'coronavirus' was used over 41,000 times in English-language print news articles and almost 19,000 times in headlines (Chaiuk \& Dunaievska, 2020). Despite the incessant reporting of the issue in the news, many Americans refuse to abide by public health and safety guidelines, such as mask-wearing, social distancing, and avoidance of crowded events, leading to further spread of the disease. According to a report published by the Pew Research Center in June 2020, people were becoming less concerned with the pandemic when in reality, the health crisis was worsening (Pew Research Center, 2020). This issue is in large part attributed to Americans' beliefs and perspectives on the pandemic, influenced by their sources of information. The way that news media and other sources frame the pandemic could be important in promoting adherence to public health guidelines. Metaphors, which are already prevalent in public discourse and news media, could be useful in achieving this goal. 
Research studies in behavioral science have shown that the way an issue is metaphorically framed can subconsciously influence people's perceptions of the issue, and thus, their behavior (Thibodeau \& Boroditsky, 2011). Metaphors have been shown to be about six percent more persuasive than normal language (Thibodeau et al., 2017). Thibodeau \& Boroditsky (2011) investigated how metaphors can influence reasoning and actions. This research demonstrated how influential widely-used metaphors are in promoting societal change. For example, the common metaphor "crime is a virus' led one crime-prevention program in Chicago to use the same prevention tactics as epidemiologists who fight AIDS and tuberculosis (Thibodeau \& Boroditsky, 2011). This study evaluated the specific effect of metaphors on behavior through five experiments. Findings included that metaphors can change the way people solve problems, metaphors can cause long-term effects on reasoning, and that people use metaphors to structure their thinking; after people are exposed to a metaphorical frame, they fit new knowledge into the metaphorical structure (Thibodeau $\&$ Boroditsky, 2011).

Due to their ability to promote understanding, persuade, and change behavior, metaphors are commonly used in the news to contextualize issues such as the COVID-19 pandemic. In general, metaphors are useful in persuading audiences; however, the type of metaphor used in certain contexts can be important in maximizing persuasion. Researchers from Oberlin and Purchase College studied the effects of two different explanatory metaphors ("guardian" and "warrior") in relation to the role of police officers in society. Throughout three studies, the researchers investigated participants' preconceived connotations regarding the two metaphors, the extent to which the explanatory metaphors were persuasive, and if the metaphors were persuasive without context. One of the studies demonstrated that the type of metaphor used to explain a concept can impact people's perspective on that concept; participants who were exposed to the "guardian" metaphor in relation to the role of police officers in society were more likely to have positive attitudes than those exposed to the "warrior" metaphor. Thus, this research emphasized the importance of choosing the correct metaphor to portray an intended view of a certain concept (Thibodeau et al., 2016).

Similarly, the way that news sources use different metaphor types to frame the pandemic could be essential in maximizing compliance with public health guidelines. Currently, the COVID-19 pandemic has been discussed on social media and in the news using metaphorical frames such as war, monster, storm, tsunami, and family (Sabucedo et al., 2020; Wicke \& Bolognesi, 2020; WHO, 2020). Additionally, other metaphor categories such as journey, control, natural force, supernatural force, and global network have been used to contextualize disease outbreaks in the past (De la Rosa, 2007). Because each metaphorical frame is different and employs different strategies of persuasion, it is important to understand the ways in which these metaphors differ in their influence on behavior. The most prevalent metaphorical frames utilize one of two strategies to persuade audiences: fear or unity/empathy.

\section{Literature Review}

\section{Fear-Producing Metaphors}

Currently, the most prevalent metaphorical frames used to discuss the COVID-19 pandemic have been ones that primarily evoke fear and anxiety, such as the war and natural disaster metaphors (Chaiuk \& Dunaievska, 2020). For example, one article published in Time is titled "Why the U.S. Is Losing the War on COVID-19" while another in Health Affairs is titled "The COVID-19 Tsunami: The Tide Goes Out Before It Comes In" (Fitzpatrick, 2020; Phillips et al., 2020). A study published in PloS One conducted a lexical analysis of COVID-19 tweets, searching for words that were associated with metaphorical frames. They found that war was the most frequent metaphor frame among COVID-19 tweets (Wicke \& Bolognesi, 2020). However, there have been arguments as to whether fear-producing metaphorical frames are the most effective in promoting adherence to health guidelines.

In one study, researchers surveyed 324 international participants, asking about their fear of contracting coronavirus, morals, political orientation, and behavior changes. They found that fear was the only factor that caused participants to positively change their adherence to public health guidelines, demonstrating that fear can influence 
behavior. The findings of this study suggest that metaphors promoting fear of coronavirus would be most effective in promoting adherence to health guidelines. However, the researchers in this study state that promoting fear and anxiety concerning the severity of the virus could produce poor mental health outcomes, which is a potential ethical limitation of the war metaphor (Harper et al., 2020). Other researchers have added to this ethical concern. According to one article in the American Journal of Public Health, fear campaigns have been ineffective in the past and tend to be used to combat health issues that are stigmatized such as addiction and overconsumption. Thus, the fear campaigns "target victims, not causes of health problems," which is not the intended purpose of health campaigns (Chapman, 2018). However, Chapman concluded that it is ethical to use fear campaigns in public health as long as the information is accurate; shielding people from accurate, alarming information with the potential to improve their health does not positively impact them (2018).

Aside from the ethical implications of fear-producing metaphors, the powerful emotion might be the most useful in increasing feelings of urgency, and thus, action. In another peer-reviewed academic journal article, researchers evaluated the influence of "war" (fear-producing) and "race" (as in competition; non-fear producing) metaphors on attitudes concerning climate change. The researchers observed that climate change discussions are often centered around monetary value, which is also true for the COVID-19 issue (people worry about how public health restrictions affect the economy). Additionally, there is a parallel between climate change and COVID-19 in the sense that both issues require global cooperation to be solved. The researchers' findings suggest that the war metaphor increases feelings of urgency and risk concerning climate change, causing more motivation to mitigate climate change than the race metaphor. Due to the similarities between the issues of climate change and COVID-19, these findings may be applicable to the COVID-19 issue in the present study (Flusberg et al., 2017).

The claims of Harper et al. (2020) and Flusberg et al. (2017) contradict those of Sabucedo et al. (2020), who asserted that the fear and anxiety the war metaphor produces can limit prosocial behavior and cause people to act selfishly, which is problematic during a pandemic. Additionally, the war metaphor implies that leaders make all of the decisions and prevent others from participating, which the authors claim is the "least recommendable political climate in situations of uncertainty and tension" (Sabucedo et al., 2020). Thus, the authors call for the metaphor of war to be replaced with one that is more associated with cooperation than combat (Sabucedo et al, 2020).

Similarly, researchers from Purchase College, University of California, Merced, and Oberlin College discussed the advantages and disadvantages of using the war metaphor in context of different social issues. In a case study, they determined that war metaphors have great emotional power and the potential to cause fear and anxiety. This fear can motivate social action and change perspectives effectively, which aligns with the findings of Harper et al. (2020) and Flusberg et al. (2017). However, the authors asserted that the effect of the metaphor depends on the context in which it is used. They specifically state that in the past, war metaphors have limited motivation when used in the context of disease. This may indicate that war metaphors are counterproductive when trying to motivate an audience to mitigate the spread of COVID-19 (Flusberg et al., 2018).

However, if the fear-producing metaphor is contextualized with messaging that informs the audience how to overcome the fear, these metaphorical frames could potentially be useful in the context of disease. A study published in Nature discussed how behavioral and social science techniques can be used to improve people's response to COVID-19 and increase adherence to public health guidelines. Their findings most relevant to the current study include that spreading fear (including through the use of metaphorical frames) can be effective if people feel capable of effectively responding to the threat but ineffective if people feel helpless to deal with the threat. Thus, if a metaphor were to spread fear, it would need to be linked with ways to address the threat of COVID-19, reducing feelings of helplessness (Van Bavel et al., 2020).

\section{Unity Metaphors}

Metaphors conveying a sense of unity and empathy like the family metaphorical frame are also being used to describe the COVID-19 pandemic. For example, the World Health Organization (WHO) launched the "We Are Family" 
campaign to promote global cooperation during the COVID-19 pandemic (WHO, 2020). These metaphors may be more useful in evoking feelings of empathy and unity during the health crisis than metaphors that primarily employ fear and anxiety. Although war metaphors may evoke some feelings of unity (against a common enemy), the authoritarian messages associated with war metaphors may overshadow feelings of unity.

In one article published in the Journal of Epidemiology and Community Health, the authors used behavioral and social science to analyze the most effective public health strategies to increase social distancing (behavioral changes due to change in perception). Among the key principles they analyze, the ones most relevant to the present study include messages promoting the protection of others, unity, and those that avoid authoritarian messages. Authoritarian messages cause a great amount of change in the short term but not in the longer term. This study asserts that messages promoting emotions other than fear and anxiety are most effective in encouraging social distancing behavior. Thus, metaphorical frames promoting fear such as the war frame (which has an authoritarian message) are expected to be less effective in promoting adherence to public health guidelines than those that emphasize unity and empathy over fear (Bonell et al., 2020). This would suggest that the family metaphorical frame would be most useful in promoting adherence to health guidelines during the pandemic, especially since this pandemic qualifies as a long term problem and the short term effects of authoritarian messages may have already subsided.

The study that suggested fear metaphors can be productive when they are paired with ways to address the crisis also placed an emphasis on the importance of cooperation during pandemics, which would support the superior efficacy of unity metaphors. News sources that spread panic and fear can undermine feelings of cooperation, which suggests that fear-related metaphors are less effective than unifying ones (Van Bavel et al., 2020). In summary, while some researchers believe that metaphors creating fear and anxiety are useful in motivating changes in behavior, others believe that this fear is counterproductive in the context of a global pandemic and metaphors promoting unity would produce more positive outcomes.

\section{Research Question}

Evidently, there is an argument among experts in social and cognitive science over which metaphor type best influences people to take action during a health crisis like the COVID-19 pandemic. While some sources claim that the fear and anxiety caused by the war metaphor are useful in motivating adherence to public health guidelines, others argue the opposite (Bonell et al., 2020; Harper et al., 2020). This raises the question of which metaphor type is the most effective in promoting adherence to health guidelines during the COVID-19 pandemic. If this question were to be addressed, sources of COVID-19 information could adapt the best metaphor type when discussing the pandemic, leading people to positively change their perception of the dangers of COVID-19 and the need to follow health guidelines. This could potentially change people's behavior (for example, increase social distancing), limiting further spread of the virus and preventing further deaths and economic damage. Due to the need for cooperation during a global pandemic and research demonstrating that fear-producing metaphors undermine feelings of unity, the researcher hypothesizes that metaphors promoting unity and empathy like the family metaphorical frame are more effective in promoting adherence to public health guidelines than metaphors promoting fear like the war metaphorical frame.

\section{Methods}

Data regarding participants' behaviors related to COVID-19 after exposure to a metaphorical frame was collected to address the research question. Based on this data, the researcher was able to determine if one metaphorical frame had a greater effect in positively changing one's behaviors than the other or the control.

The researcher conducted a post-test experimental design study, which allowed the researcher to determine which metaphor type is more effective in promoting adherence to public health guidelines. Participants (Americans 
with English fluency 18 or older) were placed into one of 2 treatment groups (war metaphor, family metaphor) or a control group (no metaphors). Although these groups were not randomly assigned, participants most likely chose the first study that appeared on their Prolific dashboard, minimizing assignment bias. The natural disaster metaphor type was excluded because the war metaphor is most prevalent in public discourse and it uses a similar strategy as the natural disaster metaphor, fear, to persuade audiences. Participants received their group's treatment through a survey.

\section{Survey Design}

The researcher created three surveys using Google Forms (questions are attached in Appendix A). The three surveys differ only in the treatment paragraph (war, family, or control). A total of four sections were included in each survey. In the first section, the informed consent form (attached in Appendix B) is included. Section 2 was labeled "Do not consent" and instructed participants to exit the study. If the participant did not consent in section 1 , they were redirected to section 2 . If they did consent, they were redirected to section 3 (treatment paragraphs). The questions regarding informed consent were required.

In the third section, a question regarding the participant's Prolific ID was included to match the participant's answers to their data in Prolific. After providing this information, participants read their assigned paragraph with a different metaphorical frame related to the COVID-19 pandemic. The war metaphor was created using elements of this metaphorical frame outlined by De la Rosa's (2007) study of metaphors used during the Avian influenza outbreak in Britain. The three paragraphs were designed using as similar sentence structure as possible in order to eliminate any confounding factors. Additionally, the same number of metaphor-related words/phrases were used in each of the war and family paragraphs. The paragraphs are displayed in Table 1.

Table 1. Treatment/Control Paragraph Structure

\begin{tabular}{|c|c|c|c|}
\hline Sentence & War & Family & Control \\
\hline 1 & $\begin{array}{l}\text { We are an army fighting to defeat } \\
\text { COVID-19, which has invaded } \\
\text { our borders. }\end{array}$ & $\begin{array}{l}\text { We are a family, uniting to evict } \\
\text { COVID-19, which is an } \\
\text { unwelcome guest in our home. }\end{array}$ & $\begin{array}{l}\text { We are all working to contain } \\
\text { COVID-19, which has disrupted } \\
\text { our lives. }\end{array}$ \\
\hline 2 & $\begin{array}{l}\text { A fierce battalion of healthcare } \\
\text { workers are sacrificing their lives } \\
\text { to defend us, because we are their } \\
\text { allies and compatriots. }\end{array}$ & $\begin{array}{l}\text { A nurturing group of healthcare } \\
\text { workers are sacrificing their } \\
\text { lives to care for us, because we } \\
\text { are their brothers and sisters. }\end{array}$ & $\begin{array}{l}\text { A large number of healthcare } \\
\text { workers are sacrificing their } \\
\text { lives to treat us, because we are } \\
\text { their clients and patients. }\end{array}$ \\
\hline 3 & $\begin{array}{l}\text { We are all soldiers fighting side- } \\
\text { by-side to reach the same goal: a } \\
\text { healthy country. }\end{array}$ & $\begin{array}{l}\text { We are all kin working together } \\
\text { to reach the same goal: a healthy } \\
\text { country. }\end{array}$ & $\begin{array}{l}\text { We are all citizens taking steps } \\
\text { to reach the same goal: a healthy } \\
\text { country. }\end{array}$ \\
\hline 4 & $\begin{array}{l}\text { We now know that masks protect } \\
\text { us from the virus; they are } \\
\text { armor. }\end{array}$ & $\begin{array}{l}\text { We now know that masks } \\
\text { protect us from the virus; they } \\
\text { are guardians. }\end{array}$ & $\begin{array}{l}\text { We now know that masks } \\
\text { protect us from the virus; they } \\
\text { are valuable. }\end{array}$ \\
\hline 5 & $\begin{array}{l}\text { We also must maintain a } \\
\text { defensive barrier of at least } 6 \\
\text { feet. }\end{array}$ & $\begin{array}{l}\text { We also must maintain a loving } \\
\text { space of at least } 6 \text { feet. }\end{array}$ & $\begin{array}{l}\text { We also must maintain a } \\
\text { distance of at least } 6 \text { feet. }\end{array}$ \\
\hline
\end{tabular}




\begin{tabular}{|c|c|c|c|}
\hline 6 & $\begin{array}{l}\text { A new vaccine is providing hope, } \\
\text { but more contagious strains of } \\
\text { the virus require continued } \\
\text { vigilance. }\end{array}$ & $\begin{array}{l}\text { A new vaccine is providing } \\
\text { hope, but more contagious } \\
\text { strains of the virus require } \\
\text { continued vigilance. }\end{array}$ & $\begin{array}{l}\text { A new vaccine is providing } \\
\text { hope, but more contagious } \\
\text { strains of the virus require } \\
\text { continued vigilance. }\end{array}$ \\
\hline 7 & $\begin{array}{l}\text { The key weapon in defeating this } \\
\text { pandemic is flattening the curve } \\
\text { by limiting contact with other } \\
\text { warriors as much as possible } \\
\text { until we can create herd } \\
\text { immunity through vaccination. }\end{array}$ & $\begin{array}{l}\text { The key to protecting our global } \\
\text { family is flattening the curve by } \\
\text { limiting contact with loved ones } \\
\text { as much as possible until we can } \\
\text { create herd immunity through } \\
\text { vaccination. }\end{array}$ & $\begin{array}{l}\text { The key to ending this pandemic } \\
\text { is flattening the curve by } \\
\text { limiting contact with other } \\
\text { people as much as possible until } \\
\text { we can create herd immunity } \\
\text { through vaccination. }\end{array}$ \\
\hline 8 & $\begin{array}{l}\text { It is crucial to shield the } \\
\text { immunocompromised, who are } \\
\text { too weak to fight for themselves. }\end{array}$ & $\begin{array}{l}\text { It is crucial to shelter the } \\
\text { immunocompromised, who } \\
\text { need extra care to survive. }\end{array}$ & $\begin{array}{l}\text { It is crucial to protect the } \\
\text { immunocompromised, who are } \\
\text { unable to deal with the virus. }\end{array}$ \\
\hline 9 & $\begin{array}{l}\text { We are at war with a deadly } \\
\text { virus, and everyone must fight to } \\
\text { reach victory. }\end{array}$ & $\begin{array}{l}\text { We are a family, faced with a } \\
\text { deadly virus, and everyone must } \\
\text { unite to protect their kin. }\end{array}$ & $\begin{array}{l}\text { We are facing a deadly virus, } \\
\text { and everyone must adhere to } \\
\text { public health guidelines to stay } \\
\text { safe. }\end{array}$ \\
\hline
\end{tabular}

Note. This table shows how the three paragraphs were created to be as similar as possible in structure and length. Metaphors are bolded, and both treatment groups have an equal number of metaphor-related words/phrases.

Each group read one of the three different paragraphs $(n=45,50$, and 51 for war, family, and control groups respectively). To ensure that participants read the paragraph, a simple question asking participants "which of the following facts is NOT included in the paragraph above?" was included. If participants answered this question incorrectly, their data was excluded from analysis.

After reading this paragraph, all participants were asked the same questions in section 4 regarding their behaviors related to adherence to public health guidelines, change in perceptions regarding the danger of the COVID19 pandemic (see manipulation check questions in Appendix A), and political affiliation. To ensure that the war and family metaphor paragraphs equally evoked the intended emotions (fear and unity/empathy respectively), manipulation checks were included in the survey. Manipulation check questions evaluated whether participants experienced increased fear or empathy as a result of their treatment. All questions were required because participants were allowed to exit the survey at any time. Manipulation check questions were the second to last set of questions so that participants were not primed to feel fear or empathy as a result of reading these questions before answering other questions. The question regarding political affiliation was the last survey question so that participants were less likely to be primed to answer other questions based on their political affiliation. Participants answered questions using a 5point Likert Scale. Questions assessed change in behavior as a result of the treatment. Higher scores on this scale indicated that participants were more likely to increase their adherence to health guidelines. There were no pre-test questions because this could have primed participants to match their post-test answers to those of the pre-test. 


\section{Recruiting Participants}

The researcher used Prolific to recruit participants to the study. The researcher created three separate studies in Prolific; each was titled "Health-related behaviors Group (A, B, or C)." The study was named without indicating that it would be investigating the effect of metaphors on COVID-19-related behavior so that participants' answers were not affected by the knowledge that the study was investigating metaphors. Group A referred to the war metaphor group, group B was the family metaphor group, and group C was the control group. Participants were not aware of their group assignment, making this a single-blind experiment. To ensure that participants did not participate in more than one study, a note was attached in the study description, directing participants to ignore this study if they had already participated in another study by this name. The study description explicitly explained the required actions of participants (read a short paragraph and answer questions about their perspectives and behaviors regarding COVID19).

The researcher entered the URLs of the corresponding Google Form into the three Prolific studies so that participants were directly brought to the survey from the Prolific platform. The researcher chose custom prescreening in Prolific and limited the age to 18-100, the Approval Rate to 100\% (to ensure that participants had been reliable in past Prolific studies), the nationality to the United States, and the fluency language to English (to ensure that participants could adequately interpret English metaphors). To determine how many participants per group would be most likely to yield significant results, the researcher ran a power analysis. The researcher used means and a standard deviation from a field test to run the power analysis. The following statistics were used: control mean $=2.917$, standard deviation $=0.87$, war group mean $=3.525$, power $=80 \%$, and $\mathrm{p}<0.0167$. The Bonferroni correction was used to account for the comparison of three groups instead of two. The mean of the war group was chosen because it had a reasonable difference in averages. The power analysis suggested that 43 participants per group was enough to yield significant results. The researcher requested 50 participants per treatment to leave room for error, 3 minutes (study completion time), and paid $\$ 0.48$ per person (total of $\$ 96.00$ ).

\section{IRB Statement}

This research required the use of human subjects. To ensure that the study was voluntary, participants affirmed that they are over the age of 18 and filled out a consent form (Appendix B). Additionally, the study's methods were reviewed by the Charlotte Mecklenburg Schools Research Review Panel to ensure that the study is humane and ethical.

\section{Data Analysis}

Averages of values reported on the Likert scale were obtained for the dependent variable (change in behavior) within each group (war, family, and control). Higher averages indicated that the paragraph increased participants' likelihood of adhering to or supporting public health guidelines. The researcher inspected the data to see if the subject variable (political affiliation) influenced averages. If it did, the researcher planned to run two separate analyses with Democrats and Independents, and Republicans and Libertarians grouped together. An analysis of variance was run to analyze the differences between means in the different groups. To evaluate whether the feelings evoked by the metaphor influenced adherence to health guidelines, a Pearson's correlation analysis was run within each of the three conditions comparing manipulation check question scores and health guideline adherence scores.

\section{Results}

Participants responded to ten questions about adherence to public health guidelines using a 5-point Likert scale in which a 5 indicated the strongest adherence and a 1 indicated the weakest adherence. Average ratings of adherence to 
health guidelines are reported in Table 2. To investigate whether the condition influenced participants' reported adherence to health guidelines, the researcher conducted a one-way between subjects Analysis of Variance (ANOVA) to compare the effect of metaphor type on average reported increases to health guideline adherence after reading the war, family, or control paragraph. There was not a significant effect of metaphor type on average reported increases to health guidelines at the $p<.05$ level for the three conditions $[F(2,143)=.59, p=.56]$.

Table 2. Means and Standard Deviations of Average Adherence to Health Guidelines Score by Condition

\begin{tabular}{|l|l|l|l|}
\hline Group & $\mathrm{N}$ & Mean & Std. Deviation \\
\hline War & 45 & 2.96 & .73 \\
\hline Family & 50 & 2.91 & .86 \\
\hline Control & 51 & 2.79 & .84 \\
\hline Total & 146 & 2.88 & .81 \\
\hline
\end{tabular}

Average ratings of fear are reported in Table 3. To investigate whether the metaphorical frames influenced participants' feelings of fear, the researcher conducted a one-way between subjects ANOVA to compare the effect of metaphor type on average ratings of fear after reading the war, family, or control paragraph. There was not a significant effect of metaphor type on average ratings of fear at the $p<.05$ level for the three conditions $[F(2,143)=.70, p=.50]$.

Table 3. Means and Standard Deviations of Fear Manipulation Check Score by Condition

\begin{tabular}{|l|l|l|l|}
\hline Group & N & Mean & Std. Deviation \\
\hline War & 45 & 2.99 & .79 \\
\hline Family & 50 & 2.91 & .94 \\
\hline Control & 51 & 2.76 & 1.07 \\
\hline Total & 146 & 2.88 & .94 \\
\hline
\end{tabular}

Average ratings of unity are reported in Table 4. To investigate whether the metaphorical frame influenced participants' feelings of unity, the researcher conducted a one-way between subjects ANOVA to compare the effect of metaphor type on average ratings of unity after reading the war, family, and control paragraph. There was not a significant effect of metaphor type on average ratings of unity at the $p<.05$ level for the three conditions $[F(2,143)=$ $2.46, p=.09]$.

Table 4. Means and Standard Deviations of Unity Manipulation Check Score by Condition

\begin{tabular}{|l|l|l|l|}
\hline Group & N & Mean & Std. Deviation \\
\hline War & 45 & 3.07 & .99 \\
\hline
\end{tabular}




\begin{tabular}{|l|l|l|l|}
\hline Family & 50 & 3.25 & 1.06 \\
\hline Control & 51 & 2.81 & .92 \\
\hline Total & 146 & 3.02 & .95 \\
\hline
\end{tabular}

Having found that the metaphors did not influence participants' feelings of fear or unity, the researcher concluded that the metaphorical frames were not strong enough to influence participants. To investigate whether the emotions evoked in individual participants were associated with responses to public health guideline adherence, a Pearson's correlation analysis was conducted comparing individual ratings of fear, unity, and reported increases in adherence to health guidelines. The correlation matrix can be seen in Table 5. Results of the Pearson correlation indicated that there was a significant positive association between ratings of fear and reported increased adherence to health guidelines, $(\mathrm{r}(146)=.70, \mathrm{p}=.00)$, a significant positive association between ratings of unity and reported increased adherence to health guidelines, $(\mathrm{r}(146)=.67, \mathrm{p}=.00)$, and a significant positive association between ratings of unity and ratings of fear, $(\mathrm{r}(146)=.58, \mathrm{p}=.00)$.

Table 5. Pearson's Correlations Among Average Ratings of Fear, Unity, and Reported Increases to Health Guidelines

\begin{tabular}{|l|l|l|l|}
\hline & $\begin{array}{l}\text { Increased Adherence to Health } \\
\text { Guideline }\end{array}$ & $\begin{array}{l}\text { Ratings of } \\
\text { Fear }\end{array}$ & $\begin{array}{l}\text { Ratings of } \\
\text { Unity }\end{array}$ \\
\hline $\begin{array}{l}\text { Increased Adherence to Health } \\
\text { Guideline }\end{array}$ & 1.00 & - & - \\
\hline Ratings of Fear & $.70^{* * *}$ & 1.00 & - \\
\hline Ratings of Unity & $.67^{* *}$ & $.58^{* *}$ & 1.00 \\
\hline
\end{tabular}

**. Correlation is significant at the 0.01 level (2-tailed).

\section{Discussion}

There was not convincing evidence to support the hypothesis that family metaphors would be more effective in promoting adherence to public health guidelines than war metaphors. It appears that the metaphorical framing in the conditions was not strong enough to influence participants' feelings of either fear or unity. However, the current results do support the role of emotions in increased adherence to health guidelines during the COVID-19 pandemic. Participants who reported stronger feelings of either fear or unity after reading a paragraph also reported higher average increases in adherence to health guidelines. These correlations support the research of Van Bavel et al. (2020), who stated that emotions "drive risk perceptions, sometimes more so than factual information." Thus, it is logical that participants who experienced stronger emotions after reading the metaphorical paragraphs perceived the risk of COVID-19 more acutely and answered survey questions reflecting this perspective. This finding suggests that if the metaphorical frames had evoked the intended emotion in participants, increases in adherence to public health guidelines might have been observed in response to these frames.

Based on the data, the researcher concludes that there is not convincing evidence that one metaphor type is more effective than another or more effective than the use of no metaphor in promoting adherence to public health guidelines during the COVID-19 pandemic. This could be because many participants are likely exposed to a high 
volume of other COVID-19 related messaging (Chaiuk \& Dunaievska, 2020). The prevalence of this issue in the news and daily conversation may overshadow any effects produced by reading the experimental paragraphs. These paragraphs are just one source of information related to COVID-19 out of the dozens that participants are likely exposed to. Additionally, due to the disruptive and traumatic nature of a global pandemic, many people are experiencing psychophysical numbing, meaning that they are becoming less sensitive to the emotions associated with death (Dyer \& Kolic, 2020). If participants are experiencing psychophysical numbing, this might prevent them from changing their behavior in response to metaphor exposure regardless of the effectiveness of the metaphor in other contexts. This produces the new understanding that neither metaphor type appears to be more effective than the other in increasing Americans' adherence to COVID-19 health guidelines when participants are exposed to an overwhelming amount of external information regarding the pandemic. Additionally, results indicate that metaphors in general have no discernible effect on COVID-19 health guideline adherence when Americans are exposed to a great deal of other information relevant to this topic.

\section{Conclusion and Future Directions}

Although there was no significant relationship observed between type of metaphor exposure and adherence to public health guidelines, this study confirmed the findings of previous studies in the context of the COVID-19 pandemic; emotions such as fear and unity have a positive relationship with change in behaviors. Additionally, this study concluded that fear-based and unity-based metaphor types do not differ in effectiveness of promoting adherence to health guidelines during the COVID-19 pandemic in its sample, possibly because the high consumption of COVID19 related news overshadows the effect of the treatment received in this study. Future studies should aim to improve the manipulation paragraphs so that the metaphors evoke greater feelings of fear or unity. The findings of further research on this topic could allow researchers to discover more effective messaging strategies to promote adherence to health guidelines. Although the COVID-19 pandemic is nearing resolution, epidemiologists are predicting that humanity has entered a pandemic era; we will likely continue to face more pandemics in the coming years (Morens \& Fauci, 2020). Thus, it is crucial to identify the most effective strategies for promoting adherence to public health guidelines for future health crises.

Metaphors have great power and the potential to motivate people to change their behavior, making it important to determine the most influential type for describing pandemics like COVID-19 (Thibodeau et al., 2017). If scientists and politicians alike were to utilize the most influential metaphor or messaging type, news sources could adapt this metaphorical frame to encourage audiences to adhere to health guidelines such as mask-wearing and social distancing, which would greatly slow the spread of COVID-19 or other future diseases.

\section{Limitations}

There are several limitations to this study. It is possible that some participants consistently gave higher ratings than other participants. This possibility is supported by the observed association between average fear and unity ratings. Although it is possible that individuals reacted to a paragraph with strong feelings of both fear and unity, if participants gave high ratings to all questions in the survey, the same pattern of results would have emerged.

Other limitations to this study include political bias concerning COVID-19 health and safety practices. A report by the Pew Research Center demonstrated how issues related to COVID-19 have further polarized Americans. Some key findings include that only $45 \%$ of Republicans are "very or somewhat concerned about unknowingly spreading the coronavirus" while " $77 \%$ of Democrats are very or somewhat concerned they might spread the coronavirus" (Pew Research Center, 2020). Furthermore, various statistics demonstrate that Republicans are more comfortable with activities associated with higher risk to contracting COVID-19 compared to Democrats. These 
results paired with the research by Thibodeau \& Boroditsky (2011) would indicate that Republicans perceive COVID19 as less of a threat than Democrats or Independents do, and they are less likely to be swayed in their reasoning by subtle metaphorical frames (Pew Research Center, 2020). Although the present study included a question regarding participants' political affiliation, there were not enough Republicans/Libertarians in the sample to conduct separate analyses. Because the sample had proportionally more Democrats/Independents than Republicans/Libertarians, it could inaccurately reflect the true average reported increase in adherence to public health guidelines score of the American population.

Another possible limitation to this study is concerning the creation of the metaphorical paragraphs. Although a published model (De la Rosa, 2007) was used as the basis of the public-health war metaphors, there were not published examples of public health family metaphors. The finding that the paragraphs did not result in reliable differences in emotional responses may indicate problems with the paragraphs' use of metaphors. The researcher's prediction that the family metaphorical frame would yield a greater positive change in behavior than the war metaphorical frame could have also influenced creation of the paragraphs. Unknowingly, the researcher could have made one paragraph more convincing than another due to bias.

\section{Acknowledgments}

I would like to thank Erika Thurman and Megan Butt (Providence High School) for all of their instruction and support throughout the research process. I am also grateful to Providence High School for providing me with the opportunity to conduct this research through its AP Capstone program.

\section{References}

Bonell, C., Michie, S., Reicher, S., West, R., Bear, L., Yardley, L., Curtis, V., Almot, R., \& Rubin, G. J. (2020). Harnessing behavioural science in public health campaigns to maintain 'social distancing' in response to the COVID-19 pandemic: key principles. J Epidemiol Community Health, 74(8), 617-619. http://dx.doi.org/10.1136/jech-2020-214290

Centers for Disease Control and Prevention [CDC] (2020). CDC COVID data tracker. https://covid.cdc.gov/coviddata-tracker/index.html\#trends_totalandratedeaths

Chaiuk, T. A., \& Dunaievska, O. V. (2020). Producing the fear culture in media: An examination on coronavirus discourse. Journal of History, Culture \& Art Research / Tarih Kültür ve Sanat Arastirmalari Dergisi, 9(2), $184-194$. https://doi.org/10.7596/taksad.v9i2.2636

Chapman, S. (2018). Is It Unethical to Use Fear in Public Health Campaigns? American Journal of Public Health, 108(9), 1120-1122. https://doi.org/10.2105/AJPH.2018.304630

Coibion, O., Gorodnichenko, Y., \& Weber, M. (2020). Labor Markets During the COVID-19 Crisis: A Preliminary View. National Bureau of Economic Research. https://dx.doi.org/10.2139/ssrn.3574736

De la Rosa, V. M. (2007). A global war against avian influenza. RaeL: Revista Electronica de Linguistica Aplicada, 6,16-30.EBSCOhost,

http://search.ebscohost.com/login.aspx?direct=true \&AuthType=ip,custuid \&custid=s8455861\&db=a9h\&AN=31971 $543 \&$ site $=$ ehost-live $\&$ scope $=$ site $\&$ authtype $=$ custuid 
Dyer J., \& Kolic, B. (2020). Public risk perception and emotion on Twitter during the Covid-19 pandemic. Applied Network Science, 5(99). https://doi.org/10.1007/s41109-020-00334-7

Fitzpatrick, A. (2020). Why the U.S. is losing the war on COVID-19. Time. https://time.com/5879086/us-covid-19/

Flusberg, S. J., Matlock, T., \& Thibodeau, P. H. (2017). Metaphors for the war (or race) against climate change. Environmental Communication: A Journal of Nature and Culture, 11(6), 769-783, https://doi.org/10.1080/17524032.2017.1289111

Flusberg, S. J., Matlock, T., \& Thibodeau, P. H. (2018). War metaphors in public discourse. Metaphor and Symbol, 33(1), 1-18. https://doi.org/10.1080/10926488.2018.1407992

Harper, C.A., Satchell, L.P., Fido, D., \& Latzman, R.D. (2020). Functional fear predicts public health compliance in the COVID-19 pandemic. Int J Ment Health Addiction. https://doi.org/10.1007/s11469-020-00281-5

Morens, D. M., \& Fauci, A. S. (2020). Emerging pandemic diseases: How we got to COVID-19. Perspective, 182(5), 1077-1092. https://doi.org/10.1016/j.cell.2020.08.021

Pew Research Center. (2020). Republicans, Democrats Move Even Further Apart in Coronavirus Concerns [Report]. https://www.pewresearch.org/politics/2020/06/25/republicans-democrats-move-even-further-apart-incoronavirus-concerns/

Phillips, R. L., Bazemore, A., \& Baum, A. (2020). The COVID-19 tsunami: The tide goes out before it comes in. HealthAffairs: leading Publication of Health Policy Research \& Insight. https:/www.healthaffairs.org/do/10.1377/hblog20200415.293535/full/

Sabucedo, J., Alzate, M., \& Hur, D. (2020). COVID-19 and the metaphor of war. International Journal of Social Psychology, 35(3), 618-624. https://doi.org/10.1080/02134748.2020.1783840

Thibodeau, P., Crow, L., \& Flusberg, S. (2016). The metaphor police: A case study of the role of metaphor in explanation. Psychonomic Bulletin \& Review, 24(5), 1375-1386. https://doi.org/10.3758/s13423-016-1192-5

Thibodeau, P. H., \& Boroditsky, L. (2011). Metaphors we think with: the role of metaphor in reasoning. PloS one, 6(2), e16782. https://doi.org/10.1371/journal.pone.0016782

Thibodeau, P. H., Hendricks, R. K., \& Boroditsky, L. (2017). How linguistic metaphor scaffolds reasoning. Trends in cognitive sciences, 21(11), 852-863. https://doi.org/10.1016/j.tics.2017.07.001

Van Bavel, J. J., Baicker, K., Boggio, P. S., Capraro, V., Cichocka, A., Cikara, M., Crockett, M. J., Crum, A. J.,

Douglas, K. M., Druckman, J. N., Drury, J., Dube, O., Ellemers, N., Finkel, E. J., Fowler, J. H., Gelfand, M., Han, S., Haslam, S. A., Jetten, J., ... Willer, R. (2020). Using social and behavioural science to support COVID-19 pandemic response. Nat Hum Behav, 4, 460-471. https://doi.org/10.1038/s41562-020-0884-z

Wicke, P., \& Bolognesi M. M. (2020). Framing COVID-19: How we conceptualize and discuss the pandemic on Twitter. PLOS ONE. https://doi.org/10.1371/journal.pone.0240010 
World Health Organization. (2020). We are family campaign. https://www.who.int/campaigns/connecting-theworld-to-combat-coronavirus/together-at-home/we-are-family-campaign 